\title{
Research on Practice Method of Polymer Materials and Engineering Professional English
}

\author{
Xuemei $\mathrm{Li}^{1, \mathrm{a}}$ \\ ${ }^{1}$ North East Dianli University, School of Foreign Languages, Jilin, Jilin Province, China \\ a18664798@qq.com
}

Keywords: Polymer Material and Engineering, Professional English, Practice Method

\begin{abstract}
Polymer Materials and Engineering is specialized polymer materials in English in college, there is the essential part of its purpose is to develop the students' ability to learn English, and English as a tool to solve practical problems. In this paper, polymer materials teaching of English existing problems on the English vocabulary teaching, teaching content, teaching methods, assessment methods, and other innovations were useful exploration. The contents and assessment methods of polymer materials and engineering bilingual teaching have been discussed based on understanding intension of bilingual teaching, in order to establish the high effective teaching mechanism. Also this study provides a novel idea of promoting the polymer materials and engineering bilingual teaching and achieving the training objectives. We should enhance the ability to understand and grasp the professional knowledge, which is an important means to achieve the internationalization of higher education in an effective way.
\end{abstract}

\section{Theoretical Introduction of Professional English}

Polymer materials and engineering English can teach students the core of the professional knowledge and core theory rather than simple English. Its purpose is to help and improve students' English learning professional knowledge and technical communication skills. Specialized polymer materials are the use of foreign language teaching in English as the main medium of instruction in Chinese to teach polymer expertise. We can get the polymer expertise from the English point of view is the core focus of the professional English teaching.

Currently polymer materials and engineering professionals involved in the English courses include: introduction of polymer materials, specializing in English as well as materials science and engineering-based courses. Various courses have different content and focus. Bilingual teaching content polymer materials and engineering generally have the following characteristics: (1) professional knowledge involves a relatively simple but more comprehensive; (2) most of the content taught in polymer chemistry, polymer physics, and other professional courses have been learned, students have a solid foundation, acceptable knowledge; (3) lower difficulty in English, teachers and students can easily explain the acceptance; (4) a cutting-edge expertise ${ }^{[1]}$.

Professional English teaching content should be involved in polymer materials and engineering expertise mainly covers the synthesis and molecular weight of the polymer, the polymer structure and properties of polymer motion and transformation, testing and characterization of polymers and plastics, fibers and polymer composites materials and other aspects. For commonly used polymeric materials such as polyethylene, polypropylene, polyvinyl chloride, nylon and polyester, etc. which should also be appropriate lesson to be introduced; addition should also include some polymer science research and an overview of cutting-edge content.

\section{Characteristic of Professional English}

Polymer Materials and Engineering professional English as a tool of polymer materials and engineering courses, teaching content to polymer materials and engineering expertise mainly for the completion of basic English transition, in order to improve students' reading ability, the specialized polymer materials literature plays an important role in helping polymer materials and engineering students to use English, learning and direct contact with foreign related information. The biggest 
difference between the polymer materials and engineering and basic English is more than long sentences, jargon, and more vocabulary. ${ }^{[2]}$. Fig.1 shows the characteristic of Professional English.

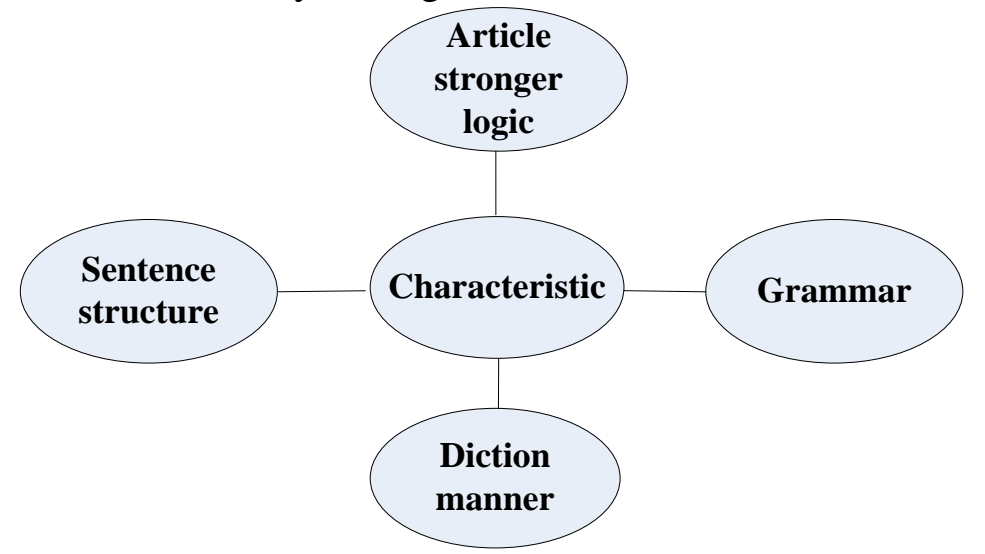

Fig. 1.The characteristic of Professional English

Polymer materials and engineering expertise combined with English textbooks closely, its contents are mostly related to Europe from the professional literature, related books and magazines, as well as an international conference papers, etc., so the differences between the maximum polymer materials and engineering English and basic English are as follows: in the article and sentence structure, professional English rigorous logic, structured, high frequency of use of long sentences, sentence structure is complex, the application of non-finite verb, multiple attributive noun structure of many; in diction, the professional terminology, professional and semi-professional vocabulary are mostly compound words and derivatives; in grammar, greater use of English passive voice; professional English often use non-verbal form of charts and express ideas and subject matter.

Professional English puts forward higher requirements for teachers' professional knowledge and English literacy, the teacher can master a large number of high molecular professional English vocabulary, English classes generate professional and teaching methods well together. In teaching the course, we must firmly grasp the teaching objectives of the course, so focused, appropriately extended, reflecting the professional characteristics, in order to ensure different levels of students receive adequate training and improve professional aspects of English proficiency. We need to guide students through a lot of practice to master English translation skills and translation standards, students will possess higher reading ability and certain professional literature translation capabilities, and write professional English abstracts ${ }^{[3]}$.

\section{Applications of Long Short Sentence}

The long sentences of polymer materials science and engineering English vocabulary include general vocabulary, vocabulary and semi-professional vocabulary. For professional vocabulary, teachers should urge students to enhance learning, and require students to remember a certain amount of specialized vocabulary, which is also consistent with the requirements of the syllabus. In teaching, teachers should strengthen the introduction of specialized vocabulary learning methods. Polymer materials and engineering has a lot of English vocabulary by adding a prefix or suffix and derived root. Generally, the new consisting vocabulary only changes the meaning of the prefix without the part of speech. Plus new word suffix constitute speech may change. Polymer materials and engineering common semi-professional English vocabulary are bond, segment, graft, block, plastic, swell, branch, group, side, flexible and so on ${ }^{[4]}$.

Usually in the polymer materials and engineering professional English, sentences often are used the present tense, past tense to express, in the description of a thing or process, we often use the passive voice. In order to avoid repetition of words and sentences, we require the use of the pronoun, gerund, participle, and infinitive master-slave structure, parallel structure, parallelism, such as the structure of language structure and parenthesis. In order to pursue the rigor and accuracy of the sentence expression clause sentence structure is also commonly used, especially in multi-attributive 
clause attributive clause and the use of very common. In order to be able to identify, locate the Italian group's guide for each word to understand the meaning of each group mean. Combined with the expertise to figure out the logic group does not agree or modification of the relationship between what is to accurately understand the sentence was intended.

English language is characterized by long sentences to express rigorous precision, so more use of long sentences, from the modification of the composition and more. Long sentences polymer materials and engineering professional English, the same modified components contain more of these components can be modified with a common object or process modification may also be a different object or process modifications. Polymer materials and engineering English translation of long sentences should be established on the basis of full understanding of the above sentence, but the sentence depends on the understanding of the grasp of the meaning of each semantic group. We should firstly determine the structure of the sentence, which includes different subject-predicate structure, the backbone of the sentence, according to the sentence appeared guide word, we find a short statement in the reading, and structure is relatively simple and easier to understand the semantics the meaning of each group. Basic English is not good enough for the students, we need to carefully analyze the relationships among populations do not agree with the logic, combined with the expertise to translate.

\section{The Practice methods of Professional English}

Training objectives polymer materials science and engineering in English can be summarized as follows: professional English courses make students be enable to master a certain amount of specialized vocabulary; which are proficient in reading professional literature than the English, we have to obtain professional research information in science academic research and take the ability to communicate; so we can have professional English translation and writing skills ${ }^{[5]}$. Fig. 2 shows the practice methods of Professional English.

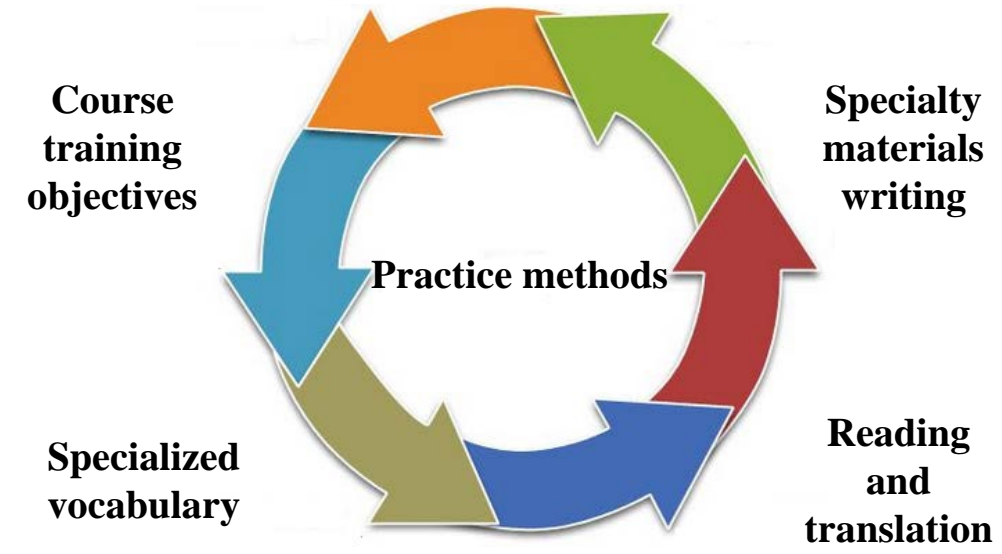

Fig. 2.The practice methods of Professional English

Polymer professional English vocabulary there are a considerable number of specialized vocabulary is by root prefix or suffix to get. Stemming add new words to change the meaning of the prefix constitute only part of speech unchanged; adding new words suffix obtained its meaning does not necessarily change, but the speech has changed. Teachers can be combined to make highlights on professional English common prefixes, suffixes, and examples. In order to remind students to pay special attention to constitute the characteristics of such specialized vocabulary, because it not only helps the professional vocabulary of memory, but also conducive to quickly grasp the meaning of articles in professional English reading and improve reading speed. For example, the meaning of the word mer means "the base", the word derived from it to get more, as monomer, dimer, polymer, polymerize, polymerization, polymeric substance and so on.

Learning Professional English is an important purpose, which makes students to have a smooth and accurate reading comprehension in English professional literature, and lay the foundation for future scientific research. Professional English translation is the relevant professional English 
articles translated into Chinese, as well as the contents of the relevant professional familiar with Chinese text material in English. We can use these often appear in the professional literature in terms of semi-professional and professional vocabulary learning together; addition to receive specialized vocabulary outside, it should be a lot of supplementary semi-professional vocabulary, so that students get to know and be familiar with these terms of use, and finally to fully grasp. In order to fully understand the characteristics of professional English sentence structure, each group of sentences can be divided to ascertain the logical relationship between the various groups, combined with their expertise to be able to successfully understand and translate the professional literature.

\section{Conclusions}

Polymer materials and scientific and technological progress has become an indispensable economic construction material, which is widely used in various fields of life, production, research and defense. With the increasingly frequent exchange of scientific and technological progress and foreign technology, and foreign language skills community colleges train professionals put forward higher requirements. In this paper, the characteristics of specialized polymer materials and the curriculum of English understanding, a clear objective professional English teaching, students learn English through the mobilization of the initiative, a reasonable choice of teaching materials and planning content, elaborate courseware and use appropriate teaching methods achieved good teaching results. Students need to focus on a variety abilities of professional English level, which are relying on each other and promote each other. It also requires teachers strive to improve their own quality, actively study and explore teaching methods to continuously improve the level of teaching references.

\section{References}

[1] Chivrac F, Pollet E, Ave'rous L. Non isothermal Crystallization Behavior of Poly(butylenes adipate-co-terephthalate)/Clay Nano-biocomposites [J], J. Polym Sci. Part B: Polym. Phys., 2007, 45: 1503-1510.

[2] Daniel Marcu, Wei Wang, Abdessamad Echihabi, and Kevin Knight .2006. SPMT: Statistical Machine Translation with Target Language Phrases [A]. In Proceedings of the 2006 conference on Empirical Methods in Natural Language Processing (EMNLP 2006) [C], 2006: 44-52.

[3] Kemal Oflazer and Durgar EI Kahlout. Exploring Different Representation Unit in English to Turkish Statistical Machine Translation [A]. In Proceedings of the Second ACL workshop on Statistical Machine Translation[C], pages, Prague, Czech, 2007: 25-32.

[4] John Hilton, David Wiley. The four 'R's of openness and ALMS analysis: frameworks for open educational resources. [J] Open Learning: The Journal of Open, Distance and e-Learning, 2010, 01(37-44).

[5] Tiffany Zenith Ivins. Localization of Open Educational Resources (OER) in Nepal: Strategies of Himalayan Knowledge-Workers[D], Brigham Young University, 2011.5. 